\title{
La música cinematográfica y la construcción del sentido en el film
}

\section{Chalkho, Rosa [ver currículum del autor, docente de la Facultad de Diseño y Comunicación]}

Resumen: La música, aún la más absoluta y exenta de referencialidades, comienza a comunicar y a producir sentido cuando está involucrada como parte del diseño de una banda sonora una escena de un filme. La misma obra que en la sala de conciertos es considerada abstracta o absoluta,puesta a significar en un filme,se constituye en un signo dentro de una cadena significante, un eslabón fundamental en la construcción general de sentido del filme. El trabajo intenta desnaturalizar este fenómeno y demostrar el funcionamiento de la música como signo en el cine.

Palabras clave: Música - Cine -

Cuadernos del Centro de Estudios de Diseño y Comunicación Nº 66

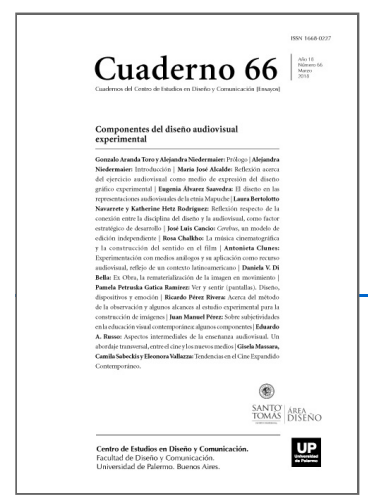

ISSN: 1668-0227

Componentes del

diseño audiovisual

experimental

Año XVIII, Marzo 2018, Buenos Aires, Argentina | 196 páginas

descargar PDF

ver índice de la publicación

Ver todos los libros de la publicación

compartir en Facebook

Semiótica - Audiovisual - géneros

musicales - significado musical.

${ }^{*}$ ) Profesora de artes en Música (UNA). Magister en Diseño (Universidad de Palermo) Doctoranda de la Facultad de Ciencias Sociales (UBA). Docente de la Facultad de Arquitectura, Diseño y Urbanismo de la UBA. Docente de grado y posgrado de la Facultad de Diseño y Comunicación de la Universidad de Palermo.

1. Sobre el significado en la música en el audiovisual

El supuesto más extendido sobre la función de la música en el cine considera como primordial al poder de lo musical para semantizar el relato, para investir de sentido a una escena y hasta para codificar los filmes mediante el sistema de géneros. Su eficacia queda demostrada con un ejercicio muy difundido entre los estudios sobre el cine, que consiste en musicalizar una misma secuencia con distintos géneros o músicas y de esta manera comprobar cómo el significado se ve modificado y hasta en algunos casos, se genera un sentido contrario a la escena original. 
La secuencia del comienzo de Theshining(1980) de Stanley Kubrick es uno de los ejemplos más evidentes de esta tesis que sostiene la manera en que la música semantiza a las imágenes. Al quitar el sonido y observarla de manera silenciosa se advierte que no existe nada en las imágenes que anticipe alguna sensación ominosa o terrorífica. Simplemente se observan tomas aéreas de bellos paisajes de montaña y un auto circulando por una ruta en un día luminoso y diáfano. Las posibilidades acerca del género al que pertenece el filme son múltiples en esta instancia silenciosa, desde una comedia o película familiar hasta una publicidad de agua mineral o nafta ecológica, pasando por una road movie: no hay nada en lo visual que invoque el terror hacia el cual Jack Torrance y su familia se encaminan.

Ahora, al repetir la secuencia con la banda sonora, todo se transforma. Desde el primer sonido interpretamos que es una película de terror y todas las imágenes que hasta el momento parecían bellas y apacibles se tornan malignas y amenazadoras: los bosques, la nieve, las sombras y hasta el punto de vista cenital aéreo o el movimiento de cámara rasante sobre el lago adoptan un cambio de significado que predice la pesadilla. El sentido resultante no se constituye como una suma o promedio de fuerzas, la placidez de las imágenes no atempera la tortuosidad comunicada por el sonido sino que la música recubre y modifica a todos los signos en una dirección dominante.

De todas las posibilidades que las imágenes silenciosas abrían, tanto de género cinematográfico como narrativas, la música ancla el sentido total de la secuencia en uno de los tantos posibles, definiendo además desde el comienzo su condición de pertenencia al género de terror.

Este ejemplo es representativo de todo un orden, una tecnología, y una manera de operar y producir la música para el discurso audiovisual, que se consolida históricamente con el establecimiento del llamado "cine clásico" o lo que Nöel Burch1 denominó Modo de Representación Institucional y poco más tarde con el advenimiento del cine sonoro en la década de 1930. Es en esta época en la que se instala el sinfonismo Post Romántico como estilo cuasi universal para la música incidental, que aunque con variantes, sigue aun hoy constituyendo el estándar de la música cinematográfica industrial.

Este orden discursivo ubica a la música incidental (o extra-diegética en el decir de Michel Chion2 ) como el elemento dilecto para la creación del clima de una escena o de toda una película, convirtiéndose en factor privilegiado de la representación de sentimientos y emociones y como elemento partícipe necesario para la codificación del género.

La música de la secuencia mencionada anteriormente es una versión en sintetizadores compuesta para la película por Wendy Carlos del Dies Irae3 , un canto gregoriano parte de la misa pro defuntis, mejor conocida como Réquiem del siglo XIII atribuido a Tomás Celano. Este canto llano fue utilizado en varias composiciones como la Sinfonía Fantástica de Berlioz, el Réquiem de Mozart, la Rapsodia sobre un tema de Paganini de Rachmaninov entre otros.

Ahora bien, ¿porqué esta música connota terror? ¿qué características sonoras y compositivas aluden a este significado?

Lo que este artículo postula es que no hay nada propio o inmanente en la música ni en los sonidos que en su esencia comporte significaciones, pero sin embargo, el sentido musical trabaja de manera efectiva, y no sólo en 
la música cinematográfica. La construcción de significados forma parte y ha sido edificada por el devenir de la trama cultural, que en un ida y vuelta entre el sentido y la interpretación se le fue atribuyendo históricamente a la música. Los significados de la música tal como los entendemos hoy nacen en la Modernidad y específicamente se experimentan con la denominada Teoría de los affetti4 , que cristaliza posteriormente en el paradigma del significado musical como expresión de las emociones y los sentimientos, en un marco y contexto en el que estos significados contemplan un alto grado de polisemia y ambigüedad propio de los discursos artísticos.

Esta dimensión cultural e histórica del sentido musical permite enunciar un segundo postulado: los procesos de significación musical se han codificado aceleradamente desde los comienzos del siglo XX como consecuencia de la utilización de la música en el cine y su gran poder de influencia en la producción social del sentido.

Si el primer supuesto enunciado al comienzo como el más extendido en los estudios de música y audiovisual considera la primacía de la función semantizadora de la música, este texto intenta poner en evidencia los resultados de un proceso inverso al estudiar la manera en que la música se ha visto afectada por su maridaje con la imagen cinematográfica.

El bucle socio-semiótico entre producción y recepción ha construido un entramado de sentidos que permiten por un lado comprender por medio de la expresión y estilo musical el carácter de la escena, los personajes, el género, etc., y por otro lado, atribuir a la música conceptos, emociones, encasillamientos, sentimientos y pertenencias a géneros que surgen de la asociación cinematográfica y que funcionan fuera de la pantalla, en la recepción musical extra cinematográfica.

Un ejemplo paradigmático de esta idea es la utilización de la parte final de la Obertura de la ópera Guillaume Tell (1829) de Gioachino Rossini que musicaliza la apertura de la serie norteamericana The Lone Ranger (19491957)

Para la discursividad social, esta música esta tanto más asociada al programa televisivo que a la ópera de Rossini, remite rápidamente a cabalgatas y westerns. Emergen de este modo invariantes o clichés en los modos de recepción musical construidos por las pantallas, que funcionan tanto para música académica pre-existente como también en partituras originales para el cine.

Las re-significaciones de la música y su valor relativo y posicional se verifican en las gramáticas de la circulación ya que la misma obra tiene connotaciones variadas dependiendo de la mediatización: Guillaume Tell tiene un sentido en la sala de conciertos mientras que adopta variantes de sentido diferentes en un programa de televisión de la década del 50 y comporta nuevas reminiscencias en su uso puntual y representativo en una cue de la nueva versión cinematográfica de 2013. Evidentemente la recepción resulta afectada por estas variaciones en tanto que los públicos masivos no especializados asocian las músicas al formato audiovisual que las popularizó.

El compositor de música cinematográfica Philipe Sarde comenta a propósito de la adaptación de obras de Bach que realizó para la película Une histoire simple (Claude Sautet, 1978)lo siguiente:

(...) es muy difícil utilizar música clásica en el cine sin modificarla. En una escena, la gente escucha música, pero enseguida, esa música se convierte en música cinematográfica. Ésta deja de ser "música de Bach" en cuanto 
pasamos al primer plano de Romy Schneider (...)5

El problema para el estudio de una semántica de la música no sólo está relacionado con la inexistencia de significados extra-sonoros para las notas o sonidos musicales discretizados sino que además la semántica queda, al menos en occidente, prácticamente anulada cuando en el siglo XVIII se impone la idea de la música absoluta.

Aún aquellas producciones que juegan con lo argumental y narrativo en un nivel semántico como la música programática de románticos y postrománticos del siglo XIX y principios del XX mantienen el absolutismo de la composición orquestal. Es imposible reconstruir el programa o relato narrativo de la Symphonie fantastique de Hector Berlioz con sólo escuchar su partitura sinfónica (y sin leer el programa) o recomponer el poema de Friedrich Nietzsche Also sprach Zarathustra escuchando solamente la música que sobre él compone Richard Strauss.

Ahora bien, desde el punto de vista referencialista, Also sprach Zarathustra, por ejemplo es una pieza cargada de significaciones que se desprenden de ella y es el cine en gran medida quien genera este entramado de significados referenciales que cubren las obras. Es a partir de la inclusión su obertura en el filme 2001: A Space Odyssey (Stanley Kubrick, 1968) que esta pieza se impregna de nuevos significados como ciencia ficción, evolución, paso del tiempo, espacio sideral, naves espaciales, inteligencia artificial, inconmensurabilidad entre otros. Del poema de Nietzsche a la película de Kubrick a través de la música de Strauss se ha construido un entramado de sentidos y mediaciones cuyos orígenes pueden quedar extraviados para la recepción masiva, pero permiten intuir que estos sentidos tampoco quedarán cristalizadas, sino que serán objeto de presentes y futuros amasados y capas temporales.

\section{La problemática del significado musical}

Ahora bien, la cuestión central que subyace en este planteo es el problema del significado musical, cuya vigencia en los debates y estudios evidencian la complejidad y actualidad del tema.

Las posiciones sobre el sentido musical pueden ubicarse a grandes rasgos, en lo que Leonard Meyer en su libro Emotion and Meaning in Music6 denominó absolutistas y referencialistas. La herencia musical occidental afianzó especialmente para la música de tradición académica la postura de la música absoluta (en el decir de Carl Dalhaus7 ), como aquella que descarta o minimiza cualquier referencia extramusical. Esta idea cristaliza con la consagración del sinfonismo del siglo XVIII.

Partiendo de la supuesta abstracción absoluta del hecho musical sería bastante tentador para los estudios de la música audiovisual sostener que los significados están aportados por el engranaje audiovisual como un efecto colateral de la experiencia musical devenida en industrialización del ocio, mientras la música mantiene su absolutismo en la sala de concierto. Sin embargo, un abordaje de los estudios musicales desde una perspectiva culturalista pone en cuestión la escisión maniquea de una supuesta pretensión abstracta de la música por un lado y una contaminación referencialista por el otro

El enfoque asumido para este trabajo es considerar a los sentidos y connotaciones musicales como significados que son resultado de una construcción socio-cultural y que no emanan naturalmente de los sonidos. El sentido 
no reside en el plano de la inmanencia sino que está construido a partir de asociaciones que el devenir sociosemiótico ha codificado con mayor o menor fortaleza. Estas asociaciones son las que nos interesa estudiar, en un marco que sostiene como indispensable la consideración del contexto y el devenir histórico para las prácticas de musicalización audiovisual.

Meyer afirma este carácter relacional de la construcción del sentido musical al enunciar que "La asociación se produce por contigüidad, es decir, algún aspecto de los materiales musicales y de su organización queda ligado, a fuer de repetirse, a una imagen referencial"8 (Meyer, 2001, p. 263). Las codificaciones en la música son procesos sociales y de arrastre histórico, y este amasado de los signos en capas temporales ha sufrido un proceso de aceleración durante el siglo XX con la utilización de la música, tanto preexistente como original, para musicalizar las películas.

En este punto cabe anticipar una conclusión: la música, que carece totalmente de analogías o mímesis con algún recorte de realidad y solamente es análoga a sí misma, revela que todos los significados de los cuales es portadora son arbitrarios; son construcciones que las culturas y sociedades edifican y transmiten históricamente con un grado tan alto de naturalización que en muchos casos encubre como personales e íntimas determinadas respuestas a músicas, que no son tan individuales, sino que responden al estereotipo social y a una codificación anterior. Cada género y cada música al sonar pone a trabajar todo un motor de significados culturales asociados y en mayor o menor medida la música se convierte en portavoz de esos sentido sociales.

Estos contextos culturales vinculados a los géneros musicales definen quizás una de las relaciones más fuertes entre música y significado: la de un género musical con sus públicos, modos de vida, de consumo, de clase, de geografía, etc. De este modo emergen las relaciones estrechas entre género musical y género cinematográfico, en asociaciones históricamente consolidadas como el film noir norteamericano de la década del '50 y el jazz, o las películas del llamado black sploitation de la década del ` 70 con el funk.

Cada género musical funciona en directa asociación con la cultura que lo ha engendrado, como lo expresa Keith Negus: "Haré hincapié en que los géneros operan como categorías sociales; en que el rap no puede separarse de la política de la raza negra, ni la salsa de lo latino, ni el country de la raza blanca y el enigma del Sur"9 .

De esta manera opera el género musical asociado a la representación de un grupo, clase o comunidad, como en el comienzo de la brasilera Cidade de Deus (Fernando Meirelles, 2002) y la frenética persecución de una gallina por las callejuelas de una favela a ritmo del samba, todo un símbolo de la música de Brasil de los sectores populares.

Ejemplos como Thesting (George Roy Hill,1973) ambientada en el Chicago de los años veinte y musicalizada con los ragtimes de Scott Joplin; o Manhattan (Woody Allen, 1979) armonizando con un jazz neoyorquino y arreglos de obras de Gershwin; o Trainspotting (Danny Boyle, 1996) y las canciones de pop y rock inglés en franca asociación con la música escuchada por los protagonistas pueden ser algunos de los tantos ejemplos de esta relación entre géneros.

3. Las codificaciones de la musicalización cinematográfica 
En efecto, la música hace al sentido cinematográfico. Pero, ¿es este significado casual, propio de cada obra? ¿Los significados funcionan al interior de cada película cómo resultado de asociaciones intrínsecas y particulares? ¿O existen invariantes y reiteraciones que permiten advertir algún tipo de codificación en la manera en que la música enuncia?

Para Michel Chion10 la codificación de la música para lo audiovisual tiene un anclaje previo al cine: su construcción vinculada a la narrativa comienza con el teatro, el ballet y la ópera. Es posible rastrear el árbol genealógico de un signo o rasgo musical en su herencia melodramática: en algunos casos estos rasgos se revelan más evidentes como por ejemplo, el valor del trino como elemento musical inestable para construir la sensación de desequilibrio. Su origen se remonta en la música occidental al periodo pre Barroco (en relación con la anteriormente mencionada Teoría de los affetti) primero relacionado con la afectación emocional y luego ya en el Barroco pleno como elemento estructural imprescindible para la construcción armónica de la cadencia. Su función era la de incrementar la tensión (reforzada con la apoyatura en disonancia de la nota superior) antes de resolver en la tónica. Trinos y trémolos funcionan como signos de tensión y su uso en la música cinematográfica ha sido y es copioso y recurrente. Baste mencionar los trinos en las cuerdas en la escena de Vertigo (Alfred Hitchcock, 1958) en la que Scottie espera a Judy, que entra ya vestida como Madeleine. Los trinos como elemento característico de esta cue semantizan la escena construyendo la tensión del personaje que espera y expresando la incertidumbre de lo inminente. La tensión generada por los trinos resuelve musicalmente y narrativamente en un clima amoroso cuando aparece Judy/Madeleine interpretada por Kim Novak.

Parafraseando a Michel Foucault este tipo de investigaciones constituyen una arqueología de los signos musicales, un rastrillaje al pasado para reconstruir el devenir del sentido de músicas o signos musicales y dar cuenta de cómo fueron producidos y pensados en cada orden cultural.

María de Arcos dedica un apartado de su libro Experimentalismo en la música cinematográfica, al ocuparse del funcionamiento del cliché y de la estandarización de la música para cine y reafirma el posicionamiento histórico previo de estas convenciones musicales: "El catálogo de clichés empleados en música de cine, en especial los que persiguen una respuesta emocional en el espectador, provienen en realidad de convenciones largamente aceptadas en el lenguaje de la música autónoma occidental"11.

Es así que mientras algunas asociaciones se pierden en pasados inalcanzables, el cine y la música cinematográfica se constituyen en un observatorio dilecto para el estudio de la vida de los signos por al menos dos razones: la primera consiste en lo reciente y cercano que resulta la emergencia del fenómeno cinematográfico en comparación con la constitución de otros discursos (la misma música) y por lo tanto la posibilidad certera de estudiar de forma tangible sus transformaciones; y la segunda, explicada anteriormente, consiste en la solidificación de los códigos de la musicalización en pos de la inteligibilidad, al menos en la mayor parte de la producción cinematográfica industrial.

Uno de los recorridos visibles de asignación de sentido que el cine le otorgó a las músicas es el valor semántico investido a las nuevas músicas del siglo XX: la música dodecafónica, la llamada música experimental o la música electroacústica, entre otras. Hacían falta nuevos sonidos para representar las temáticas extraordinarias y los instrumentos electrónicos como el Theremin o el Ondas Martenot calzan como anillo al dedo. De esta manera el cine se apropia de algunos de estos recursos sonoros para asociarlos a aliens, extraterrestres, fenómenos sobrenaturales o terroríficos. Un ejemplo que ilustra esta idea es la película Forbidden Planet (Fred 
M. Wilcox, 1956), primer largometraje con música íntegramente compuesta con medios electrónicos por el matrimonio Bebe y Louis Barron.

Esta asociación se produce también en el género de terror, donde esta nueva música o nuevos sonidos se posicionan como un elemento más de lo desconocido y por tanto como un nuevo dispositivo de producción del "miedo" en la narrativa, basándose en las raíces psicológicas del terror como el miedo a lo desconocido, como temor originario e inconsciente. Los sintetizadores, las disonancias y el atonalismo eran sonidos no escuchados hasta entonces, y se utilizaron para asociarlos a lo desconocido, lo misterioso o lo terrorífico. Nuevamente, el ejemplo de The Shining y las fantasmales voces agudas sintetizadas que Wendy Carlos diseña para la cue de los títulos se explica de esta manera.

Claro que la utilización a repetición en producción (como cualidad de la industria a repetir con leves variantes aquello que funciona) de estas características sonoro-musicales va constituyendo en la recepción de los públicos la conformación del cliché o el estereotipo. Son signos con un alto valor de codificación y en muchos casos con una baja valoración artística, ecuación a la que llega como conclusión Adorno ( ) en su crítica a las industrias de la cultura. Es en este ejemplo en el que se constata lo que se afirma al comienzo del artículo en términos de cómo la música resulta afectada por el cine: la utilización de los nuevos sonidos de vanguardias y postvanguardias del siglo XX para el Sci Fi y el terror construyó una fuerte asociación y la recepción social masiva al escuchar música contemporánea refiere que se trata de "música de terror" o "música de aliens" Russell Lack12 expresa que la música cinematográfica tiene un mensaje emocional altamente codificado, construido desde el uso de partituras pre-existentes para musicalizar el cine mudo que apela a algo que ya está internalizado en la escucha social para desencadenar una respuesta emocional adecuada en el momento apropiado. Para Lack estas convenciones han perdurado notablemente, cuestión que se verifica por ejemplo en la producción musical de John Williams, Alan Silvestre y hasta Hans Zimmer entre muchos. Pongamos por ejemplo la música de Inception (Christopher Nolan, 2010) con música de Zimmer: mientras que el film trata una idea futurista o vinculada a la ciencia ficción y el guión también presenta innovaciones asociadas a las narrativas no lineales (una historia, dentro de otra y dentro de otra construidas con sucesivas compresiones temporales) la música apela a las convenciones más seguras y efectivas. Teniendo en cuenta que Zimmer es un compositor que ha trabajado en sus comienzos con géneros de electrónica popular como el synthpopo la new wave, sus partituras permanecen en el ala más tradicional de la música cinematográfica.

En la escena de la lucha en los pasillos del hotel en un montaje alterno con el vehículo cayendo al río en el nivel de sueño anterior utiliza uno de los recursos más usados consistente en un diseño ascendente con trémolos en las cuerdas para remarcar la creciente tensión de la secuencia. ¿Por qué el diseño musical se mantendría conservador mientras los demás elementos cinematográficos juegan con la introducción de cambios? Inclusive el diseño sonoro en términos de effects, Foley effects y sonido ambiente introduce una gran cantidad de innovaciones y hasta experimentos, como llevar a límites insospechados la fidelidad del sonido con la imagen y por tanto poniendo a prueba la síncresis en la construcción de la credibilidad. La riqueza de la banda sonora "no musical" ha ido creciendo en los últimos años, a partir de la década del '90 y especialmente en el género de acción, Sci Fi y animación. Una de las posibles respuestas para explicar el conservadurismo de la composición musical es la solidez de la codificación para representar las emociones y climas de las películas.

En una escena sumamente compleja, en la que de manera alterna se muestran las escenas de un sueño dentro de otro con temporalidades distintas y además visualmente la cámara va girando según las variaciones del 
centro de gravedad de la escena, la música de manera inequívoca conduce la curva de tensión y clima de la escena.

El estereotipo musical no es simplemente una connotación negativa para el análisis fílmico sino que es la evidencia del funcionamiento del código, y el gran aporte que realiza para el esclarecimiento y comprensión del discurso.

El compositor George Antheil, autor entre otras obras de la música para el Ballet mecanique de Fernand Léger expresa, a través del comentario de su experiencia como espectador, el poder del cine de consolidar significados para las músicas:

Hollywood music is very nearly a public communication, like radio. If you are a movie fan (and who isn't) you may sit in a movie theatre three times a week listening to the symphonic background scores which Hollywood composers concoct. What happens? Your musical tastes become moulded by these scores, heard without knowing it. You see love, and you hear it. Simultaneously. It makes sense. Music suddenly becomes a language for you, without your knowing it13

No se podría explicar de manera más sencilla: la construcción de sentido se produce por la simple existencia de la asociación, y la asociación para el caso de las imágenes y los sonidos está en poder de la sincronía. Los sonidos e imágenes que suceden simultáneamente se comprenden perceptualmente como un mismo fenómeno. Una escena de amor convierte en amorosa a la música que la acompaña, a tal punto que esa música sola y en otro contexto arrastra esta impronta de sentido y es capaz a su vez de teñir con su bagaje de significados cualquier otra situación.

Una de los acuerdos más evidentes respecto a la música que el cine pacta y codifica desde sus comienzos es el de la música de foso o música extradiegética. Si bien esta modalidad tiene origen en la ópera, la narrativa cinematográfica va pretender algo que la ópera no es, en su gran mayoría este cine narrativo persigue un discurso verosímil, y una de las mayores digresiones aceptables a esta pretensión de realidad es la de la inclusión de la música de foso o extra-diegética. Esta música que no está en "ningún lado", que no sucede dentro de la historia, que los personajes no escuchan pero que de manera casi ineludible va a crear esas atmósferas o climas más orientados a provocar la emoción en el espectador que a retratar la realidad.

No hay música en la vida real durante una persecución automovilística, o cuando el asesino está acechando a su víctima o cuando dos personajes se enamoran. Pero esta inclusión musical, lejos de parecer ridícula, absurda o una traición, tanto en los comienzos del cine como hasta nuestros días, es un elemento totalmente incorporado; al punto de producirse el efecto contrario: la sensación de extrañamiento aparece cuando ella no está, sobre todo en aquellas escenas en las que su inserción está casi reglamentada, como por ejemplo en finales y conclusiones.

Hasta aquí hemos tratado la codificación musical en un sentido amplio en la búsqueda de aquellas invariantes que conforman un código entendido por muchos y aplicado de acuerdo a un sistema de géneros. Ahora bien, retomando las preguntas del comienzo del apartado, la codificación musical puede constituirse al interior de una película, a modo de un idiolecto que establece relaciones únicas pero que conserva una pertenencia codal con el sistema. 
El leitmotiv es un motivo musical, una idea o tema tanto melódico, rítmico y armónico que en un contexto audiovisual narrativo está asociado de manera recurrente a un personaje o situación narrativa. Esta categoría no es un invento cinematográfico sino que surge de la mano del género operístico, y más precisamente de la ópera romántica y post romántica. Este motivo musical es propio de cada filme y su funcionamiento construye un significado entre esta música y su representado, válido para ese film y cuya pregnante asociación produce en el espectador la idea de anticipación e inminencia.

Cuando comienza a sonar la música característica de la presencia y ataque del tiburón en Jaws (Steven Spielberg, 1975) el público "siente" premonitoriamente su presencia; y no es que esa música sea la música y mucho menos el sonido propio de un tiburón; simplemente a la segunda o tercera vez que esta asociación ocurre ya es suficiente para que estos dos hechos asociados (leitmotiv y tiburón) construyan una cadena significante en la cual la música tiene por significados tiburón, peligro, acecho, muerte o ataque.

En la mayoría de las películas esta asociación caduca cuando llega al fin, pero en algunas, como el caso de Tiburón, Psicosis14, Indiana Jones o Star Wars los motivos musicales trascienden al filme y circulan produciendo sentido según el significado que tenían en la película de origen. Otro magistral ejemplo es el leimotiv de la película Scarface (Howard Hawks, 1932), lo curioso en este ejemplo es que el leimotiv es un aria silbada por el feroz e insensible asesino Tony Camonte interpretado por Paul Muniy efectivamente el silbido es el prólogo de cada asesinato. La variante en esta película es que el leimotiv está a mitad de camino entre ser música y ser objeto sonoro. No es una música a la usanza de la época, ejecutada con una gran orquesta omnipresente, sino un simple silbido que hace el personaje. Vale cuestionar en este punto en que aspecto descansa la fortaleza o debilidad de la codificación musical: si lo fuerte del código está dado por la universalidad de su uso (en cualquier contexto silbar ese aria no tiene por significado un asesinato) o por la fortaleza que se crea en esa construcción en particular (todos los espectadores comprenden en esa película y sin lugar a dudas el significado del silbido). ¿Es más fuerte un código cuando más cantidad de espectadores lo hablan o decodifican? ¿O es fuerte por lo inequívoco de su significación, aunque sólo sea efectivo en una película?

Esta visión cambia en muchos sentidos la cuestión de la fortaleza codal, cuya variable ya no es solamente la cantidad de personas que comprenden el código, ni la universalización del código hacia toda la producción audiovisual y menos aún su inmanencia en la naturaleza tanto perceptiva visual o sonora. Una sola producción, una sola escena de una película puede articular un argot o dialecto sumamente poderoso y válido al seno de ella misma.

\section{Significado musical y parodia}

La parodia se constituye y funciona humorísticamente sobre un discurso previo, es así que cuando, la música cinematográfica es parodiada, resulta en la confirmación más rotunda de la existencia de signos y códigos. Una de las principales condiciones para que la parodia funcione es que la película original sea reconocida y, es entonces, cuando el humor actúa como en Higth Anxiety de Mel Brooks (1977) porque los filmes a los que hace referencia están canonizados, como Vértigo(1958)o The Birds(1963), entre otras citas homenaje a Alfred Hitchcock.

Brophy, el chofer que lleva al Dr. Thorndyke (Mel Brooks) del aeropuerto al instituto le insinúa que su antecesor no murió de muerte natural, al terminar la frase comienza a sonar una música inquietante, orquestada a lo 
Bernard Herrmann, pero curiosamente los dos personajes comienzan a mirar a su alrededor como buscando de donde proviene. Al instante siguiente, pasa un autobús con una orquesta dentro tocando esa música, mientras el Dr. Thorndyke respira aliviado. La música al revelarse como diegética ahuyenta la carga de mal presagio que tendría para los espectadores, el gag radica en que se escucha en la diégesis (los personajes la escuchan) lo que se supondría que es música de foso.

¿En donde radica la gracia de esta escena? Pues básicamente el humor emerge al trastocar una de las codificaciones más arraigadas del discurso audiovisual: la ubicación de la mú- sica como extradiegética. La evidencia de la arbitrariedad de la música incidental funcionando como signo emerge con fuerza provocando el gag humorístico.

Uno de los signos musicales parodiados en forma recurrente es la música de la escena del asesinato en la ducha del film Psycho (1960) de Alfred Hitchcock. Se trata del famoso motivo producido por glissandos en el sobreagudo de una orquesta de cuerdas en un ostinatto reiterativo y de ritmo regular. Un aspecto sumamente interesante es la parodia que involucra no solamente al hipotexto o película de origen, sino a todo el conjunto de convenciones y códigos que rigen al discurso audiovisual.

En el capítulo The Springfield files (Matt Groening, 1997) de The Simpsons Homero supuestamente perseguido por alienígenas abandona la carretera para introducirse en un bosque y en ese momento, a modo de inequívoca señal de alarma comienza a sonar el fragmento musical de Psycho antes mencionado. Pero abruptamente, la alarma se convierte en comedia cuando pasa un autobús llevando a los integrantes de la Filarmónica de Springfield tocando la música. ¿Qué sucedió en este fragmento? Se puede advertir una doble articulación que da sentido al gag, por un lado el ya mencionado símbolo musical de Psycho, y por el otro la parodia a High Anxiety, cuando de manera absurda aparece en la diégesis un autobús que toca la música que se suponía extradiegética.

Esta construcción de significaciones por acumulación o interacción de estamentos significantes, en forma de bucles de ida y vuelta entre las gramáticas de producción, circulación y recepción encuentra en el humor y la parodia la mayor demostración de aquellos significados instituidos y consolidados.

\section{Reflexiones finales}

Una de las aproximaciones a modo de conclusión de esta presentación es la consideración de la vida de los signos musicales en perspectiva temporal: es decir, una arqueología de la construcción de los objetos y las prácticas que devela las "capas de sentido" y sus condiciones de producción incluyendo aquellos sentidos anteriores a lo cinematográfico.

Como ejemplo podemos mencionar que hay un rasgo preexistente la obertura de Guillaume Tell ya que es una "galop", la asociación con la cabalgata existía antes como perteneciente a la danza y es nueva la relación con el western. Y son también evidentes las capas de sentido a través del ejemplo de High Anxiety y la resignificación por The Simpson.

Acerca del valor relativo que asume la música en la construcción de sentido del film resulta propicio lo que Roy Pendergast afirma al respecto: 
A related technique is the use of musical devices that are popularly associated with foreign lands and people; for example, using the pentatonic idiom to achieve an Oriental color. The "Chinese" music written for a studio film of the 1930s and ' 40 is not, of course, authentic Chinese music but rather represents our popular Occidental notions of what Chinese music is like. The Western listener simply does not understand the symbols of authentic Oriental music as he does those of Western music; therefore, Oriental music would have little dramatic effect for him"15

Que los públicos consideren como música china la música que Hollywood construyó y asoció a la cualidad de lo "chino" se revela como la comprobación de una mezcla de arbitrariedad basada en algún elemento preexistente (escala pentatónica) en las músicas y su significado.

Por otro lado, comprueba la manera en que el cine ha afectado a las escuchas en recepción la significación es construida desde el filme hacia la música. Especialmente para aquella música que a priori llega con un importante grado de abstracción y sin una carga histórica fuerte de referencialidad (como la música electroacústica) y que comienza a adoptar los significados asociados a su uso.

Otra observación que se desprende es que el proceso de construcción de significados para una música por parte del cine es cada vez más acelerado, baste con el éxito o repercusión de una idea musical asociada a una película o género cinematográfico para que una oleada de nuevos filmes en su línea narrativa utilicen este recurso y de allí en más comienza el arraigo de la significación producto de la reiteración de esa asociación.

Este tema no concluye aquí sino que se propone un enfoque para continuar investigando y abriendo nuevas preguntas acerca de investigaciones en un marco socio-semiótico de la música aplicada al discurso audiovisual.

Notas

1. Burch, Noël. (1991). El tragaluz del infinito (contribución a la genealogía del lenguaje cinematográfico. Madrid: Cátedra. Signo e imagen.

2. Chion, Michel. (1993). La audiovisión. Introducción a un análisis conjunto de la imagen y el sonido. Barcelona: Paidós

3. En latín: día de la ira.

4. La Teoría de los Affetti (Doctrine of theaffections) nace en Italia en la transición del Renacimiento al Barroco y establece pautas como combinaciones de intervalos y ritmos relacionados con la retórica de la palabra cantada mediante las cuales la música produce una emoción o afectación de los sentimientos directa en quien escucha.

5. Chion, Michel, La música en el cine. (Barcelona: Paidós, 1997), p. 255.

6. Meyer, Leonard B. Emotion and Meaning in Music (Chicago: The University Chicago Press, 1956).

7. Dalhaus, Carl, La idea de la música absoluta. (Barcelona: Idea Books, 1999)

8. Meyer, Leonard B. Emotion and Meaning in Music (Chicago: The University Chicago Press, 1956), p. 263. 
9. Negus, Keith. Music Genres and Corporate Cultures (London: Routledge, 1999) p. 30.

10. Chion, Michel. La audiovisión. Introducción a un análisis conjunto de la imagen y el sonido. (Barcelona: Paidós, 1993)

11. de Arcos, María. Experimentalismo en la música cinematográfica. (Sevilla: Fondo de Cultura Económica de España. 2006), p. 71.

12. Lack, Russell, Twenty four frames under. A buried History of Film Music. (London: Quartet Books, 2002)

13. Thomas, Tony, Music for the Movies (New York, 1973) p. 17.

14. Si bien el motivo musical de la escena más tensionante de Psicosis, el asesinato en la ducha, no es exactamente un leimotiv, la manera en que ha trascendido, circulado y convertido en símbolo, permite que se la coloque en esta categoría.

15. Prendergast, Roy.Film Music a neglected art. A Critical Study of Music in Films (New York, W.W. Norton \& Company, 1992) p. 214.

Referencias bibliográficas

Adorno, T. W. y Einsler, H. (1981). El cine y la música. Madrid: Madrid Fundamentos.

Burch, N. (1991). El tragaluz del infinito (contribución a la genealogía del lenguaje cinematográfico). Madrid: Cátedra. Signo e imagen.

Chion, M. (1993). La audiovisión. Introducción a un análisis conjunto de la imagen y el sonido. Barcelona: Paidós.

Chion, M. (1997). La música en el cine. Barcelona: Paidós.

Cooke, M. (2008). A History of Film Music. Cambridge: Cambridge University Press.

Dalhaus, C. (1999). La idea de la música absoluta. Barcelona: Idea Books.

de Arcos, M. (2006). Experimentalismo en la música cinematográfica. Sevilla: Fondo de Cultura Económica de España. Foucault, M. (2002). Las palabras y las cosas. Una arqueología de las ciencias humanas. Buenos Aires: Siglo XXI Editores. Gorbman, C. (1987). Unheard Melodies. Bloomington, Indiana: Indiana University Press.

Lack, R. (2002). Twenty four frames under. A buried History of Film Music. London: Quartet Books.

Meyer, L. B. (1956). Emotion and Meaning in Music. Chicago: The University Chicago Press.

Negus, K. (1999). Music Genres and Corporate Cultures. London: Routledge. 
Prendergast, R. (1992). Film Music a neglected art. A Critical Study of Music in Films. New York, W.W. Norton \& Company. Thomas, T. (1973). Music for the Movies. New York: A.S. Barnes.

Abstract: Music, even the most absolute and unreferenced one, begins to communicate and to produce sense when it is involved as a part of the design of a soundtrack or a film scene. Meanwhile the music performed in the concert room should be considered absolute or abstract, the meaning of the same music becomes a sign into a meaning chain, a fundamental link in the construction of the general meanings of the film. This article tries to make a demonstration of the role of music as a sign in cinema productions.

Key words: music - cinema - semiothics - audiovisual - musical genres - musical meanings.

Resumo: A música, ainda a mais absoluta e isenta de referencias, começa a comunicar e produzir sentido quando está envolvida como parte do design de uma trilha sonora de uma cena do filme. A mesma obra que na sala de concertos é considerada abstrata ou absoluta, posta num filme para dar significado, constitui um signo dentro de uma corrente significante, um elo fundamental na construção geral do sentido do filme. O trabalho intenta desnaturalizar este fenômeno e demonstrar o funcionamento da música como signo no cinema.

Palavras chave: música - cinema - semiótica - audiovisual - gêneros musicais - significado musical.

La música cinematográfica y la construcción del sentido en el film fue publicado de la página 71 a página83 en Cuadernos del Centro de Estudios de Diseño y Comunicación № 66 